\title{
Configurações
}

Revista Ciências Sociais

$10 \mid 2012$

Políticas Públicas

\section{Democracia, participação cidadã e políticas públicas: uma avaliação a partir das ações de protesto}

Democracy, citizen participation and public policy: an assessment from the actions of protest

La démocratie, la participation citoyenne et la politique publique : une évaluation des actions de protestation

\section{Ana Raquel Matos}

\section{OpenEdition}

\section{Journals}

\section{Edição electrónica}

URL: http://journals.openedition.org/configuracoes/1382

DOI: 10.4000/configuracoes. 1382

ISSN: 2182-7419

\section{Editora}

Centro de Investigação em Ciências Sociais

Edição impressa

Data de publição: 1 dezembro 2012

Paginação: 69-82

ISBN: 1646-5075

ISSN: 1646-5075

\section{Refêrencia eletrónica}

Ana Raquel Matos, « Democracia, participação cidadã e políticas públicas: uma avaliação a partir das ações de protesto », Configurações [Online], 10 | 2012, posto online no dia 17 fevereiro 2014, consultado o 10 dezembro 2020. URL : http://journals.openedition.org/configuracoes/1382 ; DOI : https://doi.org/10.4000/configuracoes.1382 


\title{
Democracia, participação cidadã e políticas públicas: uma avaliação a partir das ações de protesto
}

\author{
Democracy, citizen participation and public policy: an assessment from the \\ actions of protest \\ La démocratie, la participation citoyenne et la politique publique : une \\ évaluation des actions de protestation
}

Ana Raquel Matos

\section{Introdução}

1 Apesar da possibilidade, inerente aos sistemas democráticos, de podermos eleger quem nos represente politicamente, não temos que estar sempre de acordo com os nossos representantes em todas a matérias. $O$ desacordo e a oposição são elementos constituintes do processo político e uma condição necessária ao bom funcionamento da democracia.

2 Grande parte dos movimentos sociais e das ações de protesto que marcam a atualidade dão conta de um conflito político específico que contesta o voto enquanto espaço demasiado estreito para exercer o direito de participação na vida política e que, por isso, reivindica a transformação da democracia num sistema mais participativo, num espaço plural, sobretudo em relação a processos de decisão sobre a vida coletiva.

3 A presente abordagem propõe-se argumentar sobre os protestos enquanto espaços de participação cidadã em processos públicos de decisão, explorando a relevância dessa mobilização através do conflito.

4 Prover uma análise centrada no protesto na sua relação com a democracia não significa, porém, subscrever a tese sobre a crise da política e da democracia; pelo contrário, o presente artigo propõe-se analisar os protestos, exatamente, enquanto forma alternativa 
de estar e de fazer política para lá dos limites da democracia representativa, ou seja, uma plataforma de ação que integra o funcionamento regular da política e da democracia e que opera no sentido do seu aprofundamento.

5 Esta análise, num primeiro momento, apresenta alguns dos elementos teóricos que têm balizado a relação entre ações de protesto e democracia, incluindo as abordagens que questionam a sua legitimidade democrática, bem como os principais argumentos que potenciam a análise das ações de protesto enquanto espaços de participação cidadã com influência na definição de políticas públicas. Num segundo momento, avaliam-se essas questões a partir da análise dos protestos que ocorreram em Portugal, em 2006-2007, a propósito da decisão governamental de encerrar vários blocos de parto no país.

\section{Movimentos sociais, protestos e participação cidadã na vida política}

Desde 1960 que os movimentos sociais se tornaram elementos inextricáveis das sociedades ocidentais, sobretudo na sua relação com a democracia. A ação coletiva dos movimentos de protesto - que enquadra as possibilidades de interação entre atores politicamente relevantes a partir de ações sustentadas, de base popular, assentes em reivindicações coletivas (Tilly, 2004: 474) - tornou-se uma peça indispensável do processo político, com capacidade para afetar profundamente os seus resultados, direta ou indiretamente. Até então, esse tipo de ação caraterizava-se pela sua suposta irracionalidade, sustentada nos princípios explicativos da psicologia de multidões. Os protestos enquanto forma de ação privilegiada dos movimentos sociais eram, desta forma, encarados como indicadores de anomia social e os seus líderes equiparados a agentes mobilizados por impulsos inconscientes, seguidos por multidões irracionais (Flacks, 2005).

Um importante ponto de viragem nesta abordagem ocorreu em 1965, quando Mancur Olson introduziu nesta análise "A Lógica da Ação Coletiva". Na sua obra seminal, Olson argumenta que essas formas de ação coletiva remetem a indivíduos egoístas enquadrados em coletivos, cuja ação é definida por motivações racionais ${ }^{1}$ (1965: 108), abrindo espaço à discussão dos protestos como atos racionais, significativos, impulsionados pela necessidade de operar uma mudança social benéfica. Desde então que conflitos realizados através do protesto vêm sendo considerados ações intencionais e organizadas, do legítimo foro político, ou seja, um fenómeno normal da vida coletiva (Flacks, 2005: 54; Goodwin et al., 2001: 4; Tilly, 2004).

8 A literatura sobre este domínio distingue ainda entre "velhos" e "novos" movimentos sociais, distinção que sendo essencialmente teórica é também, naturalmente, problemática, sobretudo por nunca ter sido totalmente clara (Touraine, 2004; Estanque, 2010: 7). Os velhos movimentos sociais, constituídos pelas "velhas" ações coletivas desencadeadas desde finais do século XIX a inícios do século XX, dizem essencialmente respeito à reivindicação por direitos cívicos, políticos e sociais associados a contenciosos de classe e de trabalho. Quanto aos novos movimentos sociais, surgidos na década de 1960, resultam de novos conflitos e reivindicações decorrentes da então emergente sociedade pós-industrial, onde se enquadram os direitos estudantis, feministas, ambientalistas, pacifistas, os direitos sobre orientação sexual, raça, etnia, saúde, bem como o direito à democracia, à informação, ao pluralismo e à participação na vida coletiva (Melluci, 1980; Offe, 1985; Cohen e Arato, 1992). 
9 A passagem dos velhos aos novos movimentos sociais, mais do que uma mudança nas reivindicações que os sustentam, representa uma crítica fundamental à ordem social prevalecente e expressão central do descontentamento em relação ao modelo liberal de democracia. Os novos movimentos sociais assumem, assim, como reivindicação central a mudança a provocar no modo convencional de fazer política (Offe, 1985; Della Porta, 2003a), que deve emergir da criação de esferas públicas alternativas onde se debatam políticas, estratégias, mas também novas ideias sobre a democracia e seu funcionamento (Guidry e Sawyer, 2003: 276).

10 Os novos movimentos sociais defendem, portanto, uma democracia participativa e rejeitam o princípio (exclusivo) da delegação política que fundamenta a democracia representativa (Della Porta e Diani, 1999; Flacks, 2005). Reivindicam uma conceção de democracia a partir de baixo, em que as decisões possam ser tomadas o mais próximo possível da vida dos/as cidadãos/ãs, num movimento de defesa da descentralização política e de consulta alargada dos/ as que são afetados/as pelas decisões (Della Porta, 2003a, 2003b: 112; Diani, 2003: 47).

11 Embora distintos no que os carateriza, os movimentos sociais e os eventos de protesto são duas faces da mesma moeda. Um movimento social representa esforços coletivos, duradouros (envolvendo uma estrutura organizativa também ela duradoura), que usualmente recorre às ações de protesto como forma privilegiada de exercer pressão para a mudança (Della Porta e Diani, 1999). Enquanto os movimentos sociais fi cariam descaraterizados sem referência às ações de protesto, estas são passíveis de ocorrer fora de um movimento social específico, enquanto manifestações "momentâneas" e "espontâneas" de oposição ou de descontentamento social. Neste sentido, os protestos têm vindo a definir-se como "ações não convencionais em que canais indiretos de influência são abertos a partir da ação desempenhada por certos atores coletivos" (Della Porta e Diani, 1999: 192), ou seja, a arte performativa da política, cuja proposta é visibilizar os que não conseguem fazer ouvir a sua voz e os seus interesses (Juris, 2008).

Os protestos albergam, no entanto, na sua definição uma variedade de comportamentos que pode ir da queixa mais tímida a atos mais violentos. Representam uma espécie de comunicação participativa, sobretudo, quando o diálogo entre atores em oposição parece estar comprometido (Rudolph, 2004: 65). Esses rituais comunicativos são, assim, inseparáveis das ações de protesto, fazendo-as funcionar como fonte de informação nova sobre assuntos controversos (Burstein, 1999: 12). Esta emergência da variedade de conhecimento sobre um dado problema é também ela reveladora do potencial que os protestos exercem no estímulo ao pensamento crítico, reforçando o processo de empoderamento que este tipo de ação comporta na esfera cidadã.

Integrar uma ação de protesto pode, de facto, capacitar os/as cidadãos/ãs para uma ação política transformadora já que, isoladamente, não teriam a mesma capacidade para confrontar o Estado, nem tampouco potenciar consequências no seio de uma sociedade (Rudolph, 2004: 66). Face à intenção de transformar as práticas democráticas, os protestos podem ainda descrever-se como rituais de alta densidade (Juris, 2008), num equivalente possível a momentos de democracia de alta intensidade (Santos, 1998, 2002). 


\section{A relação entre protestos e democracia} democráticos. A relação entre movimentos sociais, suas formas de ação e democracia é, portanto, tensa e complexa (Tilly, 2003: 21-23). Assim, mesmo que tantas vezes encarados como elementos incompatíveis, democracia e contenção popular representam dois lados da mesma moeda (McAdam et al., 2001; Della Porta, 2003a, 2003b; Flacks, 2005). Os protestos, esses, compreendem formas subversivas de fazer política assentes na ideia de uma contra democracia, um espaço democrático onde se exerce vigilância e controlo sobre as instituições do Estado (Rosanvallon, 2006: 16).

Os sistemas democráticos ocidentais, na generalidade, assimilaram o direito ao protesto, reconhecendo-o legalmente, mas em muitos desses contextos esse direito, na prática, continua a ser reprimido pelos discursos políticos, objeto de repressão policial ou, muitas vezes, criminalizado. Importa por isso referir que um sistema democrático verdadeiramente inclusivo não é hostil a manifestações de protesto; pelo contrário, proporciona espaços de diálogo com essas organizações e reconhece a legitimidade da sua ação como parte do processo democrático (Burstein, 1999). Não se pode ignorar, no entanto, que, mesmo em sociedades democráticas, os protestos podem facilmente transformar-se em atos de desordem que atingem um patamar da violência que viola o exercício desse direito, em demonstração da linha ténue que separa o protesto enquanto direito democrático de atos criminosos. ${ }^{2}$

Para alguns autores, tanto os protestos "legais" como os protestos marcados pela desobediência representam formas de "poder a partir de baixo", são manifestações do poder do povo (Piven, 2008: 5; Dupuy, 2002). Para Cohen e Arato (1992), no entanto, o argumento da desobediência civil neste contexto específico de análise serve, exatamente, para demonstrar que as ações de protesto a cargo da esfera cidadã detêm a capacidade de influenciar e moldar a cultura política sem colocar em causa as instituições democráticas. Já Rancière (2004) acrescenta que a verdadeira participação política reside na criação dessa pessoa imprevisível, capaz de ocupar as ruas em protesto, considerando que é deste movimento que nasce a democracia.

Os protestos são, assim, formas de imaginar novas possibilidades de agenciamento e de reforma democrática que combatem as dinâmicas de poder que têm vindo a marginalizar certos grupos populacionais de uma participação mais ativa na vida política. Este pluralismo contencioso visa subverter os meios, os mecanismos e as ideologias geradoras de exclusão política em qualquer tipo de regime e projeta os/as cidadãos/ãs como grupos com voz na sua própria governação (Guidry e Sawer, 2003: 273-274).

18 Duas ideias centrais devem, portanto, reter-se: a) protestos e democracia reforçam-se mutuamente; b) a legitimidade da democracia não pode ser definida apenas de acordo com o respeito pelos seus processos, mas, acima de tudo, deve ser capaz de incluir, de forma eficiente, a esfera cidadã nos seus processos. 


\section{Os protestos como espaços de participação na vida política: o caso de Portugal}

19 A questão da participação democrática é, hoje, um dos desafios fundamentais do nosso tempo e um dos principais tópicos das agendas políticas nacionais e internacionais, embora as democracias liberais representativas ainda continuem a proteger os processos públicos de decisão da "intrusão" cidadã através de um processo designado de "dupla delegação" (Callon et al., 2001). De acordo com esse processo, mediante eleições regulares, os/as cidadãos/ãs delegam na esfera política e administrativa, assim como na esfera científica, a legitimidade de tomar decisões em seu nome. São estes mecanismos democráticos, representativos, que têm vindo a promover o afastamento da política dos interesses dos cidadãos, desencadeando descontentamento e desconfiança por parte da sociedade civil (Cohen e Arato, 1992), mas potenciando, por outro lado, o surgimento de novas formas de envolvimento da esfera cidadã com a política, como os protestos.

Os protestos têm-se, assim, constituído como uma dimensão negligenciada na sua relação com a participação deliberativa. Se pensarmos, por exemplo, em formas organizadas de participar em processos deliberativos como a célebre e intemporal tipologia apresentada por Sherry Arnstein (1969), questionamos onde cabe, afinal, o protesto na "escada de participação", a qual representa uma tipologia de formas participativas que vai da manipulação a mecanismos efetivos de controlo das decisões por parte dos/as cidadãos/ ãs. ${ }^{3}$ Para além de conceções formais de participação como a que representa esta tipologia de participação, existem outros processos de democratização das decisões, ou seja, outras relações entre sociedade, política e deliberação, para além das convencionais formas de participar, a que importa prestar atenção (Loeber et al., 2011: 600). Com efeito, as ações de protesto concentram, pelo menos, a mesma energia que os níveis intermédios de consulta representados na tipologia de Arnstein (1969), informando ao mesmo nível (ou até melhor) sobre as necessidades da população e suas reivindicações.

21 Assim, quando os cidadãos são privados de oportunidades para participar em decisões que os afetam ou quando as oportunidades mais padronizadas de participação não estão disponíveis ou não são adequadas para expressar a sua posição, duas situações podem emergir: 1) o crescente descontentamento com a democracia representativa; 2) a canalização desse descontentamento para oportunidades de ação que pressionem o fechamento da democracia e onde os protestos irrompem como um recurso com potencialidades para influenciar as políticas públicas. Sobre isto, a abordagem da democracia radical na sua relação com os processos deliberativos contribui com o argumento de o conflito e a luta agonística serem peças constituintes da democracia e da própria deliberação (Mouffe, 2000, 2005; Bächtinger et al., 2010).

A participação parece, no entanto, variar de acordo com os contextos nacionais e suas caraterísticas políticas e culturais, assim como dos arranjos institucionais permitidos nesses contextos democráticos (Loeber et al., 2011: 599). Entre os países da União Europeia, por exemplo, as formas de participação cidadã variam largamente. 0 mecanismo da consulta pública é, neste contexto, a ferramenta participativa mais utilizada. Já em países como Portugal, por exemplo, onde as oportunidades de participação direta nas decisões coletivas são raras e onde é evidente a ausência de espaços institucionalizados de participação deliberativa, os protestos emergem como 
alternativas para influenciar os contextos de decisão (Gonçalves et al., 2007: 114; Nunes, 2007: 67).

O defraudar das expectativas relativas à instauração de um modelo único de democracia participativa em Portugal criadas com a Revolução dos Cravos (1974-1975) e a crescente negligência da importância da participação cidadã em processos de tomada de decisão mais não tem feito do que reforçar a importância que o protesto continua a exercer na história político-social do país (Mendes, 2005; Estanque, 2010; Cerezales, 2011; Fishman, 2011; Matos, 2012).

Em Portugal, a persistência de um Estado autoritário continua, assim, a manifestar-se nas só nas relações quotidianas entre Estado e esfera cidadã como em episódios recorrentes de comportamento ilegítimo e de abuso por políticos nas suas relações com os cidadãos, organizações ou movimentos sociais que tentam exercer os seus direitos, incluindo o direito de acesso à informação e o direito de manifestação pública (Nunes, 2007: 67). A maioria dos protestos é, portanto, desvalorizada pelo Governo e o Estado como práticas participativas, os quais são regularmente ignorados ou rotulados de atos perturbadores da ordem pública (Matos, 2012).

O uso frequente do direito ao protesto por parte dos/as cidadãos/ãs constitui-se, em contextos particulares como o português, património cultural e histórico, especialmente em situações em que as pessoas sentem "na pele" os efeitos dos problemas associados à qualidade dos serviços públicos (saúde, educação, segurança, etc.), onde as políticas neoliberais afirmam cada vez com mais nitidez o recuo do Estado na proteção social e agravam a falta de acesso dos/as cidadãos/ãs aos processos de decisão política.

26 As últimas décadas são bastante ilustrativas neste sentido, revelando uma sociedade portuguesa de onde têm emergido fortes mobilizações coletivas.

\section{Os protestos sobre o encerramento de blocos de parto em Portugal como espaços de (potencial) participação deliberativa}

27 As decisões governamentais na área da saúde, em Portugal, têm-se constituído terreno fértil em protestos, sobretudo porque se apresentam herméticas à participação cidadã.

28 A análise prossegue, portanto, neste ponto, com o escrutínio de um caso empírico que ilustra os protestos como espaços de participação cidadã com potencial deliberativo: o caso dos protestos ocorridos em Portugal, entre 2006 e 2007, a propósito da decisão de encerrar vários blocos de parto e consignada pelo Despacho ministerial n7495/2006 (relativo à reestruturação dos serviços de saúde materno infantil em Portugal). ${ }^{4}$ Esta é uma medida que surge no seguimento de restruturações prévias destes serviços, às quais se vinha reconhecendo o mérito internacional do país no que toca ao seu desempenho na área da saúde materno-infantil. Um dos indicadores apontados como mais relevantes reporta à taxa de mortalidade infantil. Portugal passara, assim, dos últimos lugares no ranking mundial para figurar entre os 10 países com as mais baixas taxas de mortalidade infantil (WHO, 2011), em torno de 3,1 \%o em 2011.

$29 \mathrm{Na}$ base da polémica decisão de encerrar blocos de parto esteve então, um relatório elaborado pela Comissão Nacional de Saúde Materna e Neonatal (Portugal, Comissão Nacional de Saúde Materna e Neonatal, 2006), que avaliara estes serviços, sugerindo 
medidas a implementar. ${ }^{5}$ Entre elas, recomendava o encerramento das unidades de saúde que realizassem menos de 1500 partos por ano, um rácio indicado nesse documento como "recomendado" pela Organização Mundial de Saúde e capaz de assegurar a segurança e qualidade dos serviços a prestar. Apesar de outras sugestões terem sido avançadas pelo relatório, e das preocupações aí manifestadas em relação à necessária informação e consulta da população afetada e seus representantes políticos, o Governo avançou com um plano de encerramento cronologicamente desenhado para cumprir ao longo de $2006 \mathrm{e}$ 2007, e que veio a cumprir integralmente, baseado no critério dos 1500 partos/ano e negligenciando outras recomendações.

30 Assim, partindo do rácio 1500 partos/ano, das 50 maternidades dos serviços públicos de saúde: 27 reuniam condições técnicas para manter os blocos de parto em funcionamento e 23 não reuniam, das quais, em 15 ocorriam menos de 1200 partos/ano; em 12 menos de 1000 partos/ano; e em 5 menos de 500 partos/ano. Embora o despacho ministerial aponte para o encerramento concreto de 13 blocos de parto, por questões de fracas acessibilidades aos serviços próximos nuns locais e a potencial sobrelotação de algumas unidades noutras, esse documento acaba por consignar o encerramento de apenas nove blocos de parto no país. ${ }^{6}$

31 Foram essas nove localidades afetadas que se organizaram em fortes ações de protesto. Uma análise conjunta dessas ações no país permite-nos identificar os grandes argumentos que foram apresentados e que sustentaram a adoção dessa forma de ação coletiva.

32 Esses protestos insurgiram-se, assim, contra a falta de atenção que foi dada às questões geográficas e às especificidades demográficas, onde se inclui a discricionariedade usada pelo Governo na aplicação da medida. Sobre esta última, refira-se que o Governo não respeitou da mesma maneira o critério avançado pela CNSMN para o encerramento dos blocos de parto (1500 partos/ano), visível na decisão de manter em funcionamento, por exemplo, os blocos de parto de Cascais e Vila Franca de Xira, com um número de partos/ ano abaixo do rácio indicado, sob o argumento de que iriam sobrecarregar as maternidades de Lisboa. Além disso, embora a avaliação da CNSMN tivesse considerado algumas variáveis regionais na sua análise, tanto essa avaliação como o Governo negligenciaram as desigualdades culturais, económicas e educacionais da população na sua relação com o território. Assim, ausência da participação cidadã na decisão e a sobrevalorização das razões técnicas de que a democracia representativa se socorre resultaram em situações como a que a seguinte citação tão bem ilustra:

Não tenho carta de condução e os meios de transporte são muito caros para vir todos os dias [maternidade alternativa]. Eu não tenho dinheiro para ficar num hotel. Não tenho condições para estar com minha mulher, nem sequer para assistir ao parto do meu filho (entrevista 10).

Os protestos representaram, assim, uma tentativa de combater desigualdades a vários níveis, mas sobretudo desigualdades regionais, expressas em fenómenos como a desertificação do interior do país.

Também o tratamento desigual entre serviços públicos e privados, foi entendido neste contexto específico como um indicador claro da adoção de políticas neoliberais, tendo-se constituído num outro grande argumento que os protestos tentaram visibilizar. 0 relatório da Entidade Reguladora da Saúde (Portugal, Entidade Reguladora da Saúde, 2007) veio, aliás, a tornar claro esse tratamento desigual, já que das 28 unidades privadas de saúde com bloco de parto a funcionar na altura, apenas duas realizavam mais de 1500 
partos ano, cerca de $10 \%$, as quais não foram alvo da mesma avaliação, a partir dos mesmos critérios, nem equacionado qualquer encerramento.

Em sintonia com este argumento, verificou-se ainda que em três localidades onde encerraram serviços públicos estava já projetada a abertura dos mesmos serviços, mas de cariz privado. ${ }^{7}$ É neste contexto que esta controvérsia foi amplamente designada pelos opositores à medida como estruturada a partir de "critérios economicistas": ou seja, uma medida política que conduzida pela racionalização de recursos, mas que colocou a tónica em argumentos baseados na promoção da qualidade e segurança dos serviços a prestar. Esta é uma situação que fica bem patente - segundo alguns profissionais que também reivindicaram o direito a ser ouvidos no processo de decisão ${ }^{8}$ - na clara falta de planeamento e execução desta medida.

Eu ouvi falar do encerramento da maternidade local, mas enquanto comandante [dos bombeiros] eu nunca fui informado. Ouvi falar quando toda a gente ouviu! Nem o hospital, o INEM ou a ARS me informou da medida que estava para ser tomada. No início foi muito confuso. (...) Levámos uma mulher em trabalho de parto, já com rutura do saco das águas, para o hospital daqui e não sabíamos do encerramento e quando lá chegámos: “estes tipos estão loucos! o que é que estão a fazer aqui?!” No início nem o CODU sabia que o nosso hospital não podia fazer partos! (...) Eles fecharam as maternidades sem nunca se preocuparem se havia meios necessários. Porque se uma ambulância está fora como uma grávida durante duas horas e se houver outra emergência não há meios disponíveis. Nós nunca formos sequer consultados para saber que recursos tínhamos (entrevista 5, 2009).

Mas foi, sobretudo, a falta de transparência deste processo de decisão e a ausência de consulta/informação aos cidadãos e profissionais envolvidos - que tomaram conhecimento da medida pelos meios de comunicação social - que potenciaram fortemente o surgimento destes protestos.

Todos nós, cidadãos, não queremos que a maternidade feche. (...) Se não há condições, melhorem-nas. Não podemos é aceitar de forma leve que encerrem as coisas sem antes nos ouvirem (entrevista 2, 2009).

O próprio parlamento português, aliás, foi oficialmente informado no mesmo dia em que o despacho foi assinado e tornado público. ${ }^{9}$ Os eventos de protesto desencadeados são, assim, demonstrativos da prevalência de uma cultura democrática que ainda se carateriza por um autoritarismo excessivo do Estado, em que a tomada de decisões ocorre num espaço fechado à participação cidadã e assente na ideia de que os representantes eleitos são os exclusivos e legítimos detentores do poder de decidir a vida coletiva.

O maquinista, quando muito, serei eu. Os senhores são passageiros que representam os cidadãos", sublinhou o titular da Saúde aos deputados do seu partido, falando nas jornadas parlamentares do PS, realizadas em óbidos (declarações do Ministro da Saúde, António Correio de Campo, publicadas no Diário de Notícias, 25-02-2007).

Desta forma, uma democracia agonística, praticada a partir de ações de protesto, tem o mérito de colocar na agenda política nacional não só a necessidade de implementar uma democracia participativa, como de provocar o debate sobre a legitimidade de quem deve participar nos processos de decisão. Neste caso, estes protestos conseguiram manter a sua presença na imprensa até 2010, embora decrescendo o número de notícias publicadas ao longo do tempo. 


\section{Considerações finais} quanto à sua influência na definição de políticas públicas, mas também não se equiparam a espaços vazios de possibilidade quanto à influência que podem exercer nesses processos. Estes protestos não resultaram na concretização do seu objetivo maior impedir o encerramento dos blocos de parto -, mas demonstraram outras potencialidades. Uma delas foi a vigilância que exerceram sobre a política representativa e seus processos de tomada de decisão, tendo influído na queda do ministro responsável pela decisão analisada e na queda do governo nas eleições seguintes. Outra foi o facto de terem colocado na agenda política a questão da saúde materno-infantil e a potencial influência que exerceram no curso dessas políticas em Portugal. Protestos como estes podem, assim, equiparar-se a verdadeiros mecanismos de consulta dos/as cidadãos/ãs quanto à orientação das políticas públicas, exatamente pelo poder informativo que detêm.

Para concluir, os protestos são dotados de uma plasticidade incomum, sem limites quanto à forma e ao conteúdo. Constituem-se, portanto, como uma das principais formas de engajamento e participação dos/as cidadãos/ãs na política para além dos canais formais disponibilizados pela democracia representativa; uma declaração pública de compromisso dos/as cidadãos/ãs para com um alargamento e reforço dos modelos vigentes de política democrática. Os protestos documentam uma resposta distintiva ao que tem sido descrito como patologia de representação política e que afeta os regimes democráticos desenhados de acordo com o modelo democrático-liberal dominante. Constituem-se, portanto, num excelente palco para avaliar as relações democráticas de uma dada sociedade, tomando o pulso à abertura e qualidade da participação pública na vida política.

Configurações, 10 | 2014 


\section{BIBLIOGRAPHY}

ARNSTEIN, Sherry (1969), “A Ladder of Participation", Journal of the American Institute of Planners, 35 (4): 216-224.

BÄCHTIGER, André; NIEMEYER, Simon; NEBLO, Michael; STEENBERGEN, Marco R.; STEINER, Jürg (2010), “Symposium: Toward More Realistic Models of Deliberative Democracy Disentangling Diversity in Deliberative Democracy: Competing Theories, Their Blind Spots and Complementarities", The Journal of Political Philosophy, 18 (1): 32-63.

BURNSTEIN, Paul (1999), "Social Movements and Public Policy”, in M. Giuni, D. McAdam e C. Tilly (eds.), How Social Movements Matter, Minneapolis/Londres: University of Minnesota Press: 3-21.

CALLON, Michel; LASCOUMES, Pierre; BARTHE, Yannick (2001), Agir dans un monde incertain: essai sur la démocratie technique, Paris: Seuil.

CEREZALES, Diego Palacios (2011) Portugal à Coronhada. Protesto Popular e Ordem Pública nos séc. XIX e XX, Lisboa: Tinta da China.

CHAMBERS, Simone e KOPSTEIN, Jeffrey (2001), "Bad Civil Society”, Political Theory, 29, 6: 837-86. COHEN, Jean e ARATO, Andrew (1992), Civil Society and Political Theory, Cambridge: MIT Press. DELLA PORTA, Donatella (2003a), Introdução à Ciência Política, Lisboa: Editorial Estampa.

DELLA PORTA, Donatella (2003b) "Social Movements and Democracy at the Turn of the Millennium", in P. Ibarra (ed.), Social Movements and Democracy, Nova Iorque: Palgrave Macmillan: 105-135.

DELLA PORTA, Donatella e DIANI, Mario (1999), Social Movements: An introduction, Cornwall: Blackwell Publishing.

DIANI, Mario (2003), “Direct Democracy and Leadership in Social Movement Networks", in P. Ibarra (ed.), Social Movements and Democracy, Nova Iorque: Palgrave Macmillan: 47-59.

DUPUY, Jean-Pierre (2002), Pour une catastrophisme éclair, Paris: Seuil.

ESTANQUE, Elísio (2010), "Sindicalismo e movimentos sociais: Ação coletiva e regulação social no contexto europeu e português", Revista Lutas Sociais, 23, PUC_São Paulo, (disponível em http:// www.ces.uc.pt/myces/UserFiles/livros/477_EE_Lutas\%20Sociais_Sind\%26MSs.pdf).

FISHMAN, Robert (2011), "Democratic Practice after the Revolution: The Case of Portugal and Beyond", Politics and Society, XX(X): 1-35.

FLACKS, Dick (2005), “A questão da relevância nos estudos dos movimentos sociais”, Revista Crítica de Ciências Sociais, 72: 45-66.

GONÇALVES, Maria Eduarda (Coord.); DELICADO, Ana; BASTOS, Cristiana; RAPOSO, Hélder; DOMINGUES, Mafalda (2007), Os portugueses e os novos riscos, Lisboa: Imprensa de Ciências Sociais. GOODWIN, Jeff; JASPER, James; POLLETTA, Francesca (2001), “Why Emotions Matter”, in J. Goodwin, J. Jasper and F. Polletta (eds.), Passionate Politics. Emotions and Social Movements, Chigago: The University of Chicago Press: 1-24. 
GUIDRY, John A. e SAWYER, Mark Q. (2003), “Contentious Pluralism: The Public Sphere and Democracy", Perspetives on Politics, 1: 273-289.

JURIS, Jeffrey (2008), “Performing Politics. Image, Embodiment, and Affective Solidarity during Anticorporate Globalization Protests", Ethnography, 9 (1): 61-97.

LOEBER, Anne; GRIESSLER, Erich; VERSTEE, Wytske (2011), "Stop Looking Up the Ladder: Analyzing the Impact of Participatory Technology Assessment from a Process Perspetive", Science and Public Policy, 38(8): 599-608.

MATOS, Ana Raquel (2012), "Birthing democracy": Between birth policies in Portugal and mothering new forms of democracy in Brazil, Tese de Doutoramento apresentada à Faculdade de Economia da Universidade de Coimbra, Coimbra: Universidade de Coimbra.

MCADAM, Doug; TARROW, Sidney e TILLY, Charles (2001), Dynamics of Contention, Cambridge: Cambridge University Press.

MELLUCI, Alberto (1980), “The new social movements”, Social Science Information, 19: 199-226.

MENDES, José Manuel (2005), “"Só é vencido quem deixa de lutar»: Protesto e Estado democrático em Portugal”, Revista Crítica de Ciências Sociais, 72: 161-185.

MOUFFE, Chantal (2000), "Deliberative Democracy or Agonistic Pluralism”, Reihe Politikwissenschaft/Political Science Series, 72, (disponível em http://www.ihs.ac.at/publications/ $\mathrm{pol} / \mathrm{pw}_{-}$72.pdf).

MOUFFE, Chantal (2005), The Democratic Paradox, Londres: Verso.

NUNES, João Arriscado (2007), “Governação, Conhecimentos e Participação Pública”, Relatório de Provas em Sociologia apresentado à Faculdade de Economia da Universidade de Coimbra, Coimbra: Universidade de Coimbra.

OFFE, Claus (1985), "New Social Movements: Changing Boundaries of the Political", Social Research , 52: 817-868

OLSON, Mancur (1965), The Logic of Collective Action, Cambridge: Harvard University Press.

PIVEN, Frances Fox (2008), “Can power from the below change the world?”, American Sociological Review, 73: 1-14.

PORTUGAL, Comissão Nacional de Saúde Materna e Neonatal (2006), Organização Perinatal Nacional. Programa de Saúde Materna e Neonatal, Lisboa: Comissão Nacional de Saúde Materna e Neonatal.

PORTUGAL, Entidade Reguladora da Saúde (2007) Caracterização dos Prestadores de Cuidados de Saúde com Centros de Nascimento, Lisboa: Entidade Reguladora da Saúde.

RANCIÈRE, Jacques (2004), Aux bords du politique, Paris: Gallimard.

ROSANVALLON, Pierre (2006), La contre-démocratie, Paris: Éditions du Seuil.

RUDOLPH, Susanne Hoeber (2004), “Is Civil Society the Answer?” in S. Prakash e P. Selle (eds.), Investigating Social Capital, Nova Deli/Thousand Oaks/Londres: Sage: 64-87.

SANTOS, Boaventura de Sousa (1998), Reinventar a democracia, Lisboa: Gradiva.

\section{NOTES}

1. Esta é uma questão-chave que levanta alguns problemas, desde logo porque pressupõe definir o que é "racional" e "irracional" e para quem. Em teorias como a de Olson, por exemplo, 
"egoísmo" e "interesse" aparecem associados à racionalidade, enquanto a "indignação" à irracionalidade.

2. Esta abordagem não ignora, portanto, o facto de os protestos poderem traduzir-se em atos extremamente violentos e com impactos adversos na sociedade e na democracia (Tilly, 2003, 2004). Na verdade, o conceito de má sociedade civil circunscreve tais movimentos em oposição à democracia (Chambers e Kopstein, 2001).

3. Segundo Arnstein (1969) diferentes formas de participação cidadã distribuem-se ao longo dos degraus de uma escada de oito degraus, que vão desde a manipulação (situada na base), terapia, informação, pacificação, parceria, poder delegado até ao controle pelos cidadãos (no topo) dos processos de tomada de decisão. A "escada da participação" torna-se, portanto, ilustrativa dos vários níveis que a arquitetura institucional sobre envolvimentos dos cidadãos nas decisões tem assumido, embora nem todos os degraus traduzam formas de participação efetiva.

4. Este caso foi analisado com detalhe na tese de doutoramento da autora (fi nanciada pela FCT Ref ${ }^{a}$ SFRH/BD/40971/2007). Os dados que aqui se apresentam derivam de uma abordagem qualitativa elaborada a partir de 27 entrevistas semiestruturadas realizadas com atores privilegiados neste processo, realizadas entre 2008 e 2010, análise documental (relatórios, legislação, protocolos sobre saúde maternoinfantil) e análise de imprensa (dos jornais diários Jornal de Notícias e Diário de Notícias e do seminário Expresso), num total de 1114 publicadas entre 2004 e 2010, das quais 497 foram analisadas ao abrigo dos pressupostos da referida tese de doutoramento (Matos, 2012).

5. Foi esta avaliação que sustentou a decisão. Na base da controvérsia esteve o facto de este relatório ter sido entregue ao ministro da tutela quatro dias antes da assinatura do despacho que consagrou os encerramentos, num claro indicador, de acordo com os opositores à medida, de que a medida estaria já tomada, esperando-se apenas a sua necessária fundamentação técnica.

6. Amarante, Barcelos, Chaves, Elvas, Figueira da Foz, Lamego, Mirandela, Oliveira de Azeméis e Santo Tirso.

7. Mais concretamente em Chaves, Mirandela e Santo Tirso

8. Obstetras das unidades a encerrar, profissionais ligados ao serviço de transporte de doentes urgentes e alguns médicos de clínica geral e familiar.

9. De acordo com o art. 12..$^{(g)}$ da lei n. 27/2002, de 8 de novembro, é da responsabilidade do Ministério da saúde encerrar serviços. Esta não é, portanto, uma matéria sujeita a discussão parlamentar prévia ou sua aprovação.

\section{ABSTRACTS}

O presente trabalho faz uma breve revisão da literatura enquadradora do protesto enquanto forma de ação coletiva na sua relação com a democracia e enuncia os principais pressupostos que sustentam os protestos enquanto espaços de participação cidadã na definição de políticas públicas recorrendo, para tal, a um caso empírico concreto: os protestos que ocorreram a propósito do encerramento de blocos de parto em Portugal, entre 2006 e 2007. Esta abordagem consagra, assim, espaço à reflexão sobre os potenciais impactos que essa forma de ação coletiva pode exercer em processos deliberativos, na vida pública e na própria democracia.

This paper briefly reviews the body of literature that frames protest events as forms of collective action in its relation to democracy, as well as the main assumptions underpinning protests as 
spaces for citizen participation in public policies conception. These questions are discussed upon a concrete empirical case: the protests that occurred in Portugal between 2006 and 2007 due to the closure of several maternity wards. This approach establishes thus space to reflect on the potential impact that this form of collective action can exercise in deliberative processes, in public life, and on the democracy itself.

Cet article fait une brève révision de la littérature de la protestation comme une forme d'action collective dans sa relation avec la démocratie et énonce les principaux arguments qui soutiennent ces manifestations de protestation comme des espaces de participation citoyenne dans la définition des politiques publiques, utilisant un cas empirique concret: les manifestations de protestation qui ont eu lieu au Portugal entre 2006 et 2007 à propos de la fermeture des salles d'accouchement. Cette approche établit ainsi un espace à la réflexion sur les potentiels impacts que cette forme d'action collective peut exercer dans les processus délibératifs, dans la vie publique et dans la démocratie elle-même.

\section{INDEX}

Mots-clés: manifestations de protestation, participation citoyenne, délibération, démocratie

Keywords: protests, citizen participation, democracy

Palavras-chave: protestos, participação cidadã, deliberação, democracia

\section{AUTHOR}

\section{ANA RAQUEL MATOS}

Centro de Estudos Sociais da Universidade de Coimbra, amatos@ces.uc.pt 